\title{
EL CENSO DE MANUFACTURAS DE 1784. UNA IMAGEN DEL SECTOR TRANSFORMADOR ESPAÑOL PARA UNA POLITICA INDUSTRIAL
}

por

ISABEL MIGUEL, LÓPEZ

Universidad de Valladolid.

RESUMEN: El Censo de Manufacturas de 1784 constituye una fuente documental que, como tal, babia permanecido inédita basta abora. A través de sus testimonios es posible acercarse a los contrastes que presentaba el sector transformador bispano de la época, tanto en los tipos de unidades de producción como en el equipamiento, mano de obra utilizada, consumo de materias primas o en el producto obtenido. Asimismo transmite los problemas y sugerencias planteados desde las distintas manufacturas y ámbitos del Reino, sobre los que se conserva información, proyectando la imagen de una actividad económica en proceso de cambio.

Palabras Clave: España, Siglo XVII, Historia económica, Censo, Manufacturas, Industria.

ABSTRACT: The 1784 "Censo de Manufacturas" represents a source that bas been unknown up to now. This document shows differences in the units of production, the production equipment, the labour force employed, the raw materials consumed and the products obtained. In the same way, it points out the problems and suggestions posed from the different activities and lands of the kingdom, on which information basbeen preserved, reflecting the picture of an economic activity that is being transformed.

KEY wORDS: Spain, 18th century, Economic History Census, Manufacturing, Industry.

\section{INTRODUCCIÓN*}

Sugería Jovellanos en la década de los ochenta del siglo XVIII que «es preciso conocer el país antes de trabajar en favor de su felicidad» ' ${ }^{1}$. Este tipo de

* Esta exposición forma parte de los proyectos de investigación «Fuentes documentales y materiales para la historia de la industria en Castilla y Leóns y «La industrialización de Castilla y Leóny financiados por la Junta de Castilla y León y la DGICYT, $\mathbf{n}^{\circ}$.PB93-0223, respectivamente.

1 Jovel Asturias sobre los medios de procurar la felicidad en aquel Principadom.- Obras.- B.A.E., T. L- pág. 442.

Hispania, LVIII/3, núm. 200 (1998) 1021-1044 
pensamiento parece haber guiado el quehacer de los gobiernos españoles de la época, puesto que propiciaron una dinámica de información, en la que movilizaron a los organismos administrativos e instituciones que les permitieran acercarse a la realidad del Reino. Entre los procedimientos arbitrados para recabar noticias destacaron los formularios, a modo de encuesta, que, al igual que en Francia desde la aplicación del Colbertismo ${ }^{2}$, se convirtieron en España, tras la llegada de los Borbones, en un mecanismo frecuente de recogida de datos por parte del Estado, pero al que también recurrieron particulares en su afán de conocimiento, aunque los resultados tuvieran diversa fortuna.

Precisamente, la documentación generada en una de estas operaciones informativas, inédita hasta ahora, verificada por medio de la Junta General de Comercio, Moneda y Minas ${ }^{3}$, constituye el núcleo de interés de esta exposición, así como la imagen que proyectan sus mensajes acerca del sector transformador español de aquella centuria.

\section{OPERACIÓN INFORMATIVA}

\section{I.1. Gểnesis y alcance geogräfico}

La expresión Censo de Manufacturas de 1784 alude al registro de datos y noticias proporcionados por las respuestas a una encuesta emanada de la Junta General de Comercio en diciembre de $1783^{4}$, tras el final de un periodo bélico, ante la necesidad de relanzar la producción, de reformar el sector transformador por las expectativas de mercado que parecía suponer la normalizada vigencia del Reglamento de Comercio Libre con América de 1778 y para enfrentarse a la afluencia de productos extranjeros que hacían la competencia a los hispanos. En este sentido, el móvil esgrimido para acometer la empresa era la necesidad de "fomentar y proteger las manufacturas e industrias en estos Reinos", para lo que resultaba imprescindible disponer de una «Razón sobre el estado de las fábricas y los estorbos y medios para vencerlos» ${ }^{5}$.

A fin de obtener las noticias deseadas, se solicitó la colaboración de los Intendentes y subdelegados de la Junta de Comercio, pero también la de los Administradores Generales de Rentas Provinciales y de partidos en cada una de las provincias, ya que "por sus empleos se podría esperar lo practicasen con Edición.

2 GILLE (1980): Les sources statistiques de l'bistoire de France- Droz S.A.- Genève.- Segunda

3 Larruga, (1789): Historia de la Real y General Junta de Comercio, Moneda y Minas.Madrid. Sobre el tema MOLAs, P.(1978): “La Junta General de Comercio y Moneda. Las Instituciones y los hombres». - Cuadernos de Historia, t.IX.- Instituto Jerónimo Zurita.- Zaragoza.

4 ARCHIVO GENERAL DE SIMANCAS (A.G.S.), Dirección General de Rentas, II Remesa, leg. 503.

5 La orden circular y la argumentación de esta iniciativa, cuyo contenido se incluye en el fondo del Archivo de Simancas indicado, fue registrada por Larruga (1789), t. IX, pp. 523-525.

Hispania, LVIII/3, num 200 (1998) 1021-1044 
acierton, advirtiendo que la combinación de datos recibidos por ambas vías proporcionaría ventajas a la hora de conocer lo que se calificaba de «estado razonable» de las fábricas. La llegada de la primera remesa de respuestas a través de la Dirección General de Rentas resultó alentadora porque «adjuntan noticias que no dan los Intendentes», argumento que se utilizó para apremiar a los que todavía faltaban por remitirlas.

Ante la desaparición de la mayor parte del Archivo de la Junta General de Comercio, a la que se enviaron las comunicaciones, ha sido, pues, el camino de la Dirección General de Rentas el que ha permitido acceder al conocimiento de algunos detalles y resultados del proceso de recogida de informes que se inicia en enero de 1784, con el envio de circulares sobre el tema ${ }^{6}$ a los distintos Administradores, adjuntando la «Razón», de la que se difundieron 600 ejemplares.

El esmero y empeño puesto en esta actuación se manifiesta, entre otros gestos, en el meticuloso seguimiento de la operación, pues tras esperar el año 1784 la recepción de los datos solicitados y observar que eran varias las Administraciones que no los habían expedido, se envió un oficio, en abril de 1785, a todas y cada una de las remisas, que se reiteró en marzo y octubre de 1786, verificando recordatorios nominales a los que todavía no habían cumplido.

$\mathrm{La}$ consecuencia de la perseverancia fue que las respuestas obtenidas en la $\mathrm{Di}$ rección General de Rentas abarcaban una gtan parte del territorio hispano ${ }^{7}$ (Mapa I), a diferencia de experiencias precedentes. La cartografia de la documentación recibida al final de 1787, que puede considerarse, por el momento, el término del proceso y utilizando la división administrativa del siglo XVIII, permite apreciar que las ausencias totales de respuesta afectan a las Provincias Exentas, aunque estas no aparecían en ninguna telación inicial ${ }^{8}$, Extremadura, Cuenca, Guadalajara, la cual aduce escasez de oficiales para realizar el encargo, y Canarias. A ellas se añadirían faltas en Sevilla (a excepción de las jurisdicciones de Antequera y Puerto de Santa María), Burgos (salvo el territorio de La Montaña), Salamanca (menos la Administración de Ciudad Rodrigo) y Soria (excluída la Administración de Agreda). Por lo que respecta a Valencia parece que sí respondió, por cuanto en una de las relaciones de recepciones de 1787 se indica que el informe había sido (evacuado», sin embargo la documentación no ha sido hallada, conservándose, únicamente, el testimonio de la ciudad de Alicante y su jurisdicción. En cuanto a Madrid, no se alude a ella en ningún momento del proceso, por lo cual su circunscripción no dispone tampoco de noticias en este Censo, quizá nunca solicitadas por ya conocidas.

G Se elaboraron tres tipos de circulares diferenciadas por pequeños matices para ser dirigidas a los Administradores Generales de Aduanas, a los Administradores Generales de Rentas Provinciales y una tercera para Administradores específicos que fueron los de Zaragoza, Ciudad Rodrigo, Zamora, Barcelona y Valencia.

7 La información recogida afecta en torno al 70 por ciento de la superficie de España que representaba alrededor del 63 por ciento de la población.

8 A pesar de no encontrarse en las primeras relaciones de control, sin embargo en un papel suelto sin fecha, que pudiera datarse en 1787 , se menciona por primera vez al administrador de Vitoria y al de Pamplona como participantes en este proceso. 


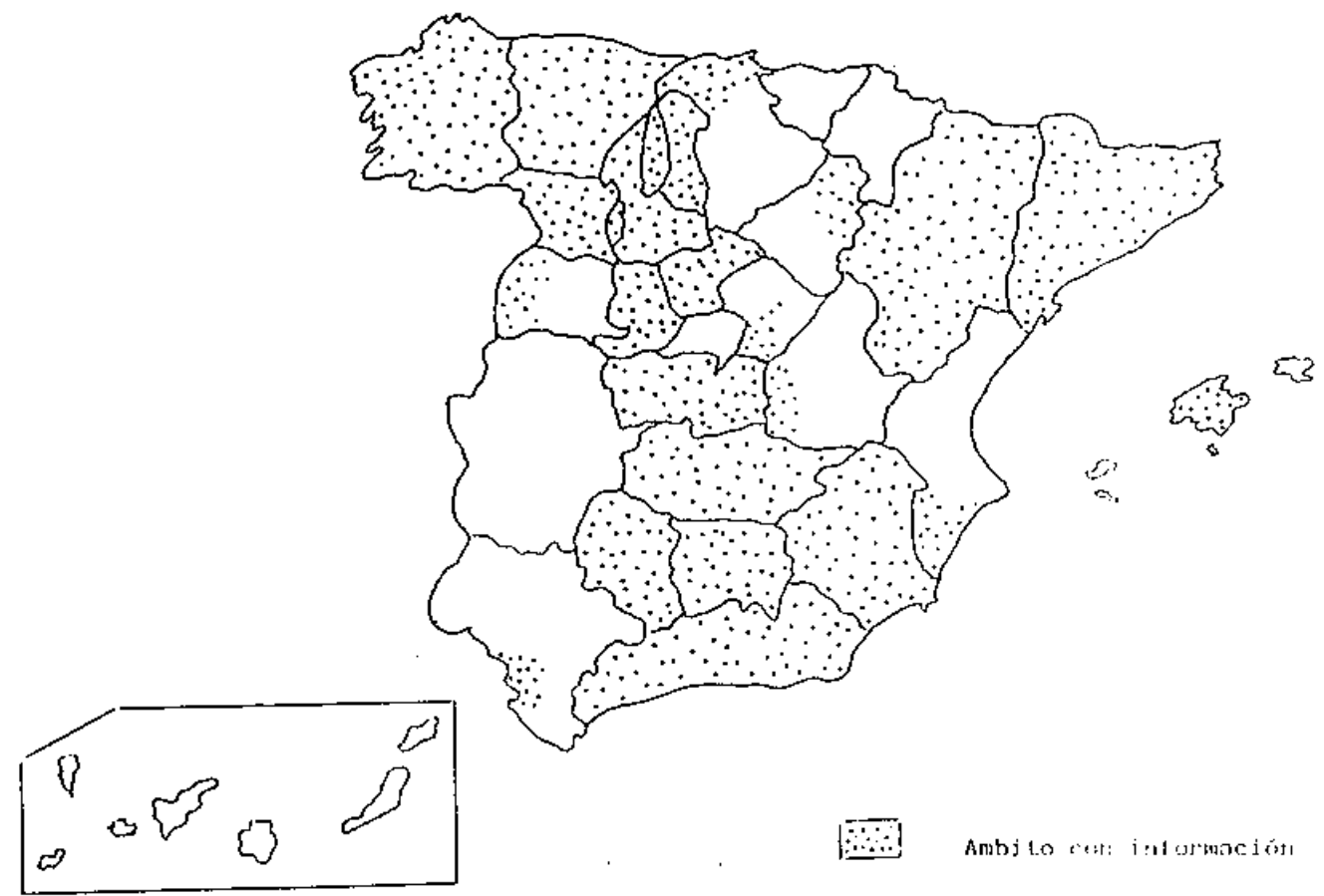

\subsection{Contenido previsto en la Encuesta}

La «Razón», a partir de la que se elaboró toda la información, presentaba los rasgos de una encuesta específicamente industrial que incluía un amplio repertorio de cuestiones relacionadas con actividades del sector transformador español consideradas básicas por sus autores. Se demandaba sobre las fábricas de tejidos de las distintas fibras y variedades, haciendo hincapié en el algodón y la obtención de su hilado, sobre las condiciones técnicas en las que se llevaba a cabo el trabajo y la dotación de que se disponía para hilar, tejer, abatanar, teñir, estampat o ptensar. Igualmente se interrogaba acetca de las «fábricas» de curtidos, loza, papel, calderas de jabón, martinetes y ferrerías, así como sobre las manufacturas de esparto, cordelería y jarcia, sin olvidar las minas y su estado. Además, se requería en todos los quehaceres el número de trabajadores y la cuantía de la producción, debiendo adjuntar «en las de más consideración»

Hípantia, LVIII/3, núm. 200 (1998) 1021-1044 
el nombre de los dueños. A fin de incluir todo lo destacable se advertía que se debía mencionar «cualquier rama de la industria de las que no se comprenden en esta Razón o producciones útiles al comercio y fábricas...» (Apéndice I). La información cuantitativa de los item planteados se acompañaría de la valoración cualitativa de los uestorbos» que las fábricas tenían y de las propuestas para «resolverlos».

A diferencia de requerimientos inmediatamente anteriores relacionados con el sector transformador (1773 y 1779) o posteriores (1789) que volcaron sus pesquisas en el textil o en el curtido (1775), esta encuesta de 1784 ofrecía una mayot amplitud de pretensiones, a pesar de la falta de mención explicita de ciertas actividades (agroalimentaria o naval), que pudieron considerarse incluídas en ese "cualquier rama de la industria...» con el que se cierra la Razón, puesto que sí fueron recogidas en varios informes.

\subsection{Algunas consideraciones sobre las respuestas}

La evaluación de los datos derivados de esta Encuesta ha de tener en cuenta, previamente, que no se trata de una fuente documental de carácter fiscal, de forma que, a pesar de haber utilizado la vía de la Dirección General de Rentas, los Administradores no señalaron, expresamente, reticencias en las declaraciones como argumento para justificar posibles fallos, con excepción de dos casos, Segovia y Murcia ${ }^{9}$, aunque ambos dejaron constancia de su afán por cumplir el encargo superando los obstáculos.

En cuanto al criterio espacial concebido para la recogida de noticias fue la localidad, donde los justicias actuarían como agentes informantes ${ }^{10}$, lo que debería conferir a los resultados una mayor exactitud por el mejor conocimiento de las realidades inmediatas. No obstante, también, pudiera posibilitarse la introducción, en algún caso, de intereses no necesariamente apropiados para la obtención de resultados rigurosos. De cualquier modo, al disponer de una amplia gama de referencias los contrastes de situaciones en las actividades manufactureras españolas quedan asegurados, por cuanto eran todos los convocados

9 El Administrador de Segovia aducia que el Intendente habia prevenido para que se le negasen las noticias porque sólo se las debían das a el, pero además se quejaba de que «los interesados creyendo las solicitan para más derechos se tienen atrás, responden confusamente a lo que se les pregunta o sin rebozo reniegan de ello. Pero, en fin, podrá servir para esclarecer por mayor los asuntos que se indicany. En términos similares, el Administrador de Murcia, además de subrayar la falta de subalternos, indicaba que «basta que los pida un Administrador de Rentas Provinciales para que le nieguen u oscurezcan, por el temor del aumento de contribuciones...».

10 En el conjunto de las respuestas sólo Aragón y el territorio montañés utilizan otra estructura en la confección del documento, que es la de distribuirlo por actividades ajustándose al orden de la Razón, no por localidades en las que se citan las distintas manufacturas, fórmula esta última que utiliza la mayoría. Por otro lado, en Galicia y en el partido de León se recurtió simultáneamente a las circunscripciones de parroquia y concejo para emitir los datos.

Hippania, LVIII/3, núm. 200 (1998) 1021-1044 
a declarar, no sólo los más importantes, ni los que reunieran determinadas condiciones.

Por lo que respecta a los afanes de cuantificación, tal como se solicitaba, este Censo merece un gran reconocimiento, lo que no es óbice para apreciar que, en general, se resienten los datos de empleo y producción, aunque la minuciosidad de las respuestas a estos temas varía no sólo entre provincias, sino entre localidades dentro de cada provincia y entre sectores. Destacan globalmente las informaciones cifradas de Cataluña, Aragón, Palencia, Jaén, Mallorca, así como las del partido de León o la Administración de Ciudad Rodrigo por su carácter más exhaustivo, mientras resulta llamativa la escasez numérica del informe de la ciudad de Granada en sectores claves o la vaguedad de las respuestas gallegas referidas a la industria linera.

Otras observaciones, que pueden realizarse, están en relación con la utilización del contenido informativo en la época. Así, el documento elaborado para este Censo sobre el espacio de la Montaña en 1784 fue copiado literalmente por el autor (J.M.) del conocido como «Estado de las fábricas, comercio, industria y agricultura en las Montañas de Santanden, datado en 1798, quien confesaba «inspirarse» en un informe anterior, resultando ser de catorce años antes ${ }^{11}$. La estructura del escrito, el análisis de los «estorbos» y las valoraciones de problemas que realizó el Administrador santanderino, Diego Tricio Nájera, en los años ochenta, se los apropió J.M., aunque éste omitió algunos detalles sobre las ferrerías y casi la totalidad de los remedios que Tricio había sugerido, sustituyéndolo por informaciones sobre los montes y la matrícula del mar. Por lo demás, sólo esporádica y puntualmente el autor del «Estado...» se permitió añadir ciertas aportaciones personales.

En el mismo sentido, todo el fondo documental fue conocido por Larruga quien lo utilizó en sus «Memorias políticas y económicas» ${ }^{12}$ para aquellos ámbitos sobre los que trabajó, lo que se constata meridianamente en las referencias a los territorios de Toledo y Ciudad Real, porque apenas ofrece otro dato distinto del momento, mientras en los demás volúmenes de esta obra se enmascaran las noticias del que denominamos Censo de Manufacturas de 1784 entre otras cifras de las que, a veces, el archivero de la Junta de Comercio no indica cronología precisa, llegando a hacer suyas opiniones que habían vertido los Administradores en sus informes.

Asimismo, la importancia concedida a las noticias adquiridas mediante la Encuesta condujo a la confección de un compendio de las mismas en un sólo documento, pero el proceso de compilación se interrumpió bruscamente, por lo que hoy se dispone, en ciertos casos, del resumen ${ }^{13} \mathrm{y}$ de la documentación primaria generada por cada Administración de Rentas o por cada localidad. In-

11 Estado de las fäbricas, comercio, industria y agriculiura de las Montañas de Santonder (S.XVIII).Introducción histórica de Tomás Martínez Vara.- Eds. Estudio.- Santander.- 1979.

12 LARRUGA (1787-1800): Memorias politicar y econímicas sobre los frutos, comercio, faibricas y minas de España.- Madrid.- 45 vol.

13 A.G.S., D.G.R., II Remesa, leg. 497.

Hispania, LVIIL/3, núm. 200 (1998) 1021-1044 
cluso, los datos del Censo se utilizaron de referencia para valorar la evolución de la industria, cuando, en 1790, se preguntó al Administrador de Barcelona sobre la variación que se había producido con respecto a la Relación de 1784.

En suma, constituye la expresión de un esfuerzo cuantificador y sistemático en medio de una tendencia de la época a la descripción cualitativa, vertida en Memorias, Informes o Discursos de la que el Censo no se aparta totalmente, por cuanto incorporaba la percepción de los estorbos y las propuestas para superarlos.

\section{EL CENSO DE 1784 Y LA REAIIDAD MANUFACTURERA ESPAÑOLA}

El análisis de la información constitutiva de este Censo permite disponer de una panorámica, salvando las lagunas, de la situación del sector transformador en un momento concreto ${ }^{14}$. De ella se exponen, a continuación, breves pinceladas ${ }^{15}$ como acercamiento a una actividad económica que ocupaba, a finales del siglo XVIII, aproximadamente al $17 \%$ de la población activa ${ }^{16}$ y que tenía en el sector textil al mayor absorbente de empleo, puesto que acogía en torno al $90 \%$ de los empleados industriales declarados en este Censo, aunque es preciso considerar que bastantes personas de las registradas trabajaban a tiempo parcial.

\section{II.1. Sobre la distribuciôn geográfica de las actividades transformadoras}

La tepresentación cartográfica de las manufacturas sobre las que se preguntaba, utilizando como criterio los telares en uso o los establecimientos en funcionamiento, permite apreciar algunos rasgos sobre su localización, según la información disponible ${ }^{17}$.

14 Análisis regionales sobre Aragón, Andalucía y Cataluña pueden encontrarse en Migues, I. (1994): «E1l sector manufacturero aragonés en el Censo de 1784».- Revista del Instituto Jerónimo Zurita, 69-70.- Zaragoza.- págs. 193-224. (1995): «El sector manufacturero andaluz en el Censo de 1784». Revista de Estudias Regionates, N. 41, págs. 65-114. (1996): «El Censo de Manufacturas de 1784. Una nueva fuente para el análisis de la historia industrial de Cataluñan.Revista de Historia Económica, XIV, 1.- págs. 125-181.(1994), (1995), (1996).

15 Se trata de un avance del estudio global sobre la fuente documental, la cual fue presentada por primera vez en el Seminario de Historica Económica «La desindustrialización a partir de la industrialización”, ditigido por Jordi Nadal, que tuvo lugar en Soria, en julio de 1996, bajo los auspicios de la Fundación Duques de Soria.

16 PLAZA (1976): Estructura económica de España en el siglo XVIII. Madrid. pág. 184. VVAA. (1985): España en el S. XVIII. Homenaje a Pierre Vilar. Crítica. Madrid. VVAA. (1982): Tres estudios de bistoria económica de Aragón. Zaragoza. VV.AA. (1988): La industrialización del norte de España. Eds. Critica. Barcelona.

17 Se han incorporado, puntualmente, para la elaboración de los mapas que se aportan, datos complementarios de furentes diversas que se especifican en cada momento, cuando existian núcleos destacados en alguna actividad, a escala del Reino, de los que el Censo no proporcionaba información al respecto. 
Así, entre las especialidades textiles más difundidas, las mayores concentraciones laneras se encontraban en ambas Castillas, Cataluña, el entorno alcoyano ${ }^{18}$, la zona Rubielos-Villarroya de los Pinares, Jaca, Mallorca, Ios ejes Pozoblanco-Bujalance y Antequera-Grazalema (Mapa II). Mientras, la manufactura de lino sobresalía en Galicia, Mallorca y Andalucía, aunque existian espacios muy notables entre el Pisuerga y el Sil y en Aragón (Mapa III). Por su parte, el arte de la seda se pre-

MAPA II

TEJIDO DE LANA

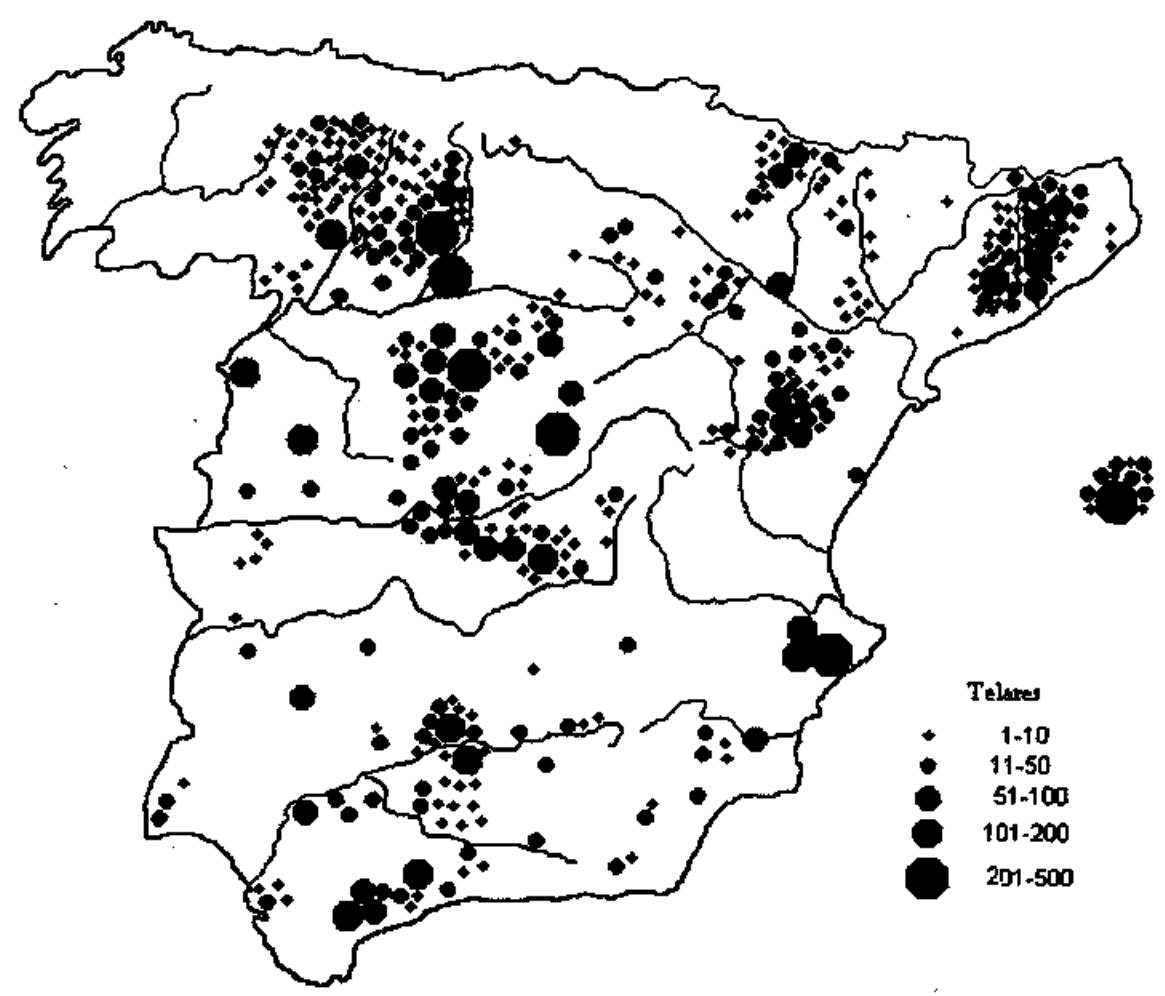

18 En el mapa II se utiliza la cifra del núcleo de Guadalajara ofrecida por González (1980), p. 336, para el área alcoyana datos de 1771 y para Extremadura los correspondientes al Infome de 1779 , del que procede el resto de la información correspondiente a esta última región.

Hispanja, LVIII/3, núm. 200 (1998) 1021-1044 


\section{MAPA III \\ TEJWO DE LNO/CÁÑAMO}

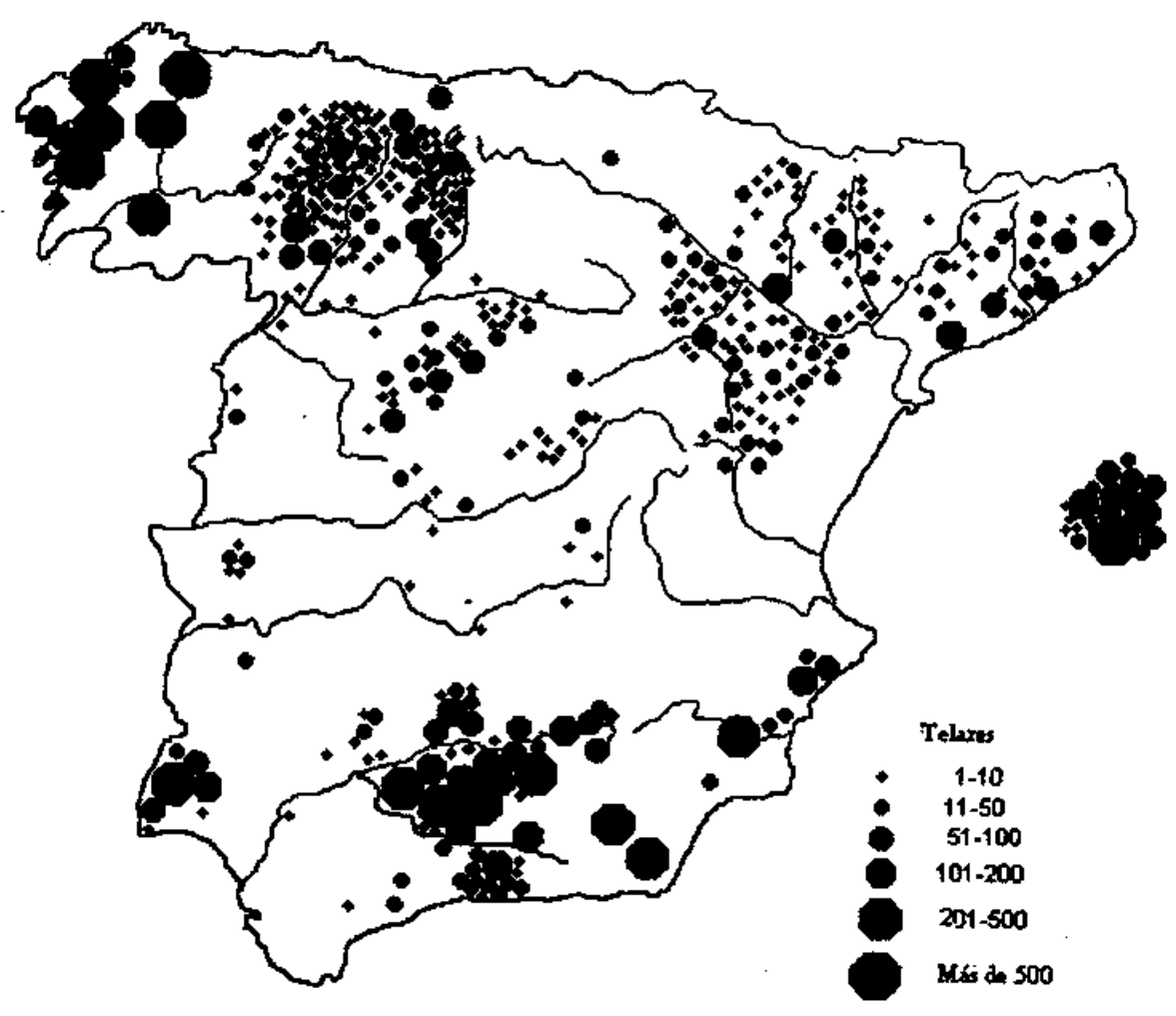

sentaba mucho más polarizado en Andalucía, Cataluña, Toledo y Valencia ${ }^{19}$ (Mapa IV). Máxima concentración adquiría el tejido del algodón, ubicado en Cataluña, y especialmente en Barcelona, ya que sólo se registraba un tejedor de muselinas en Palma de Mallorca y otro de colchas de algodón en Puente Genil, si bien las telas con mezcla de algodón se realizaban en localidades de Valencia ${ }^{20}$, Aragón, Andalucía o Castilla y se hilaba esta fibra también en Palma de Mallorca y Jerez (Mapa V).

19 Se utilizan en el mapa IV para Valencia los datos recogidos por Martinez Santos, V. (1981): Cara y cruz de la sederia yalenciana (S.XVII-XIX). Valencia. pág. 96.

20 Según referencias disponibles de 1771 para el territorio valenciano. 


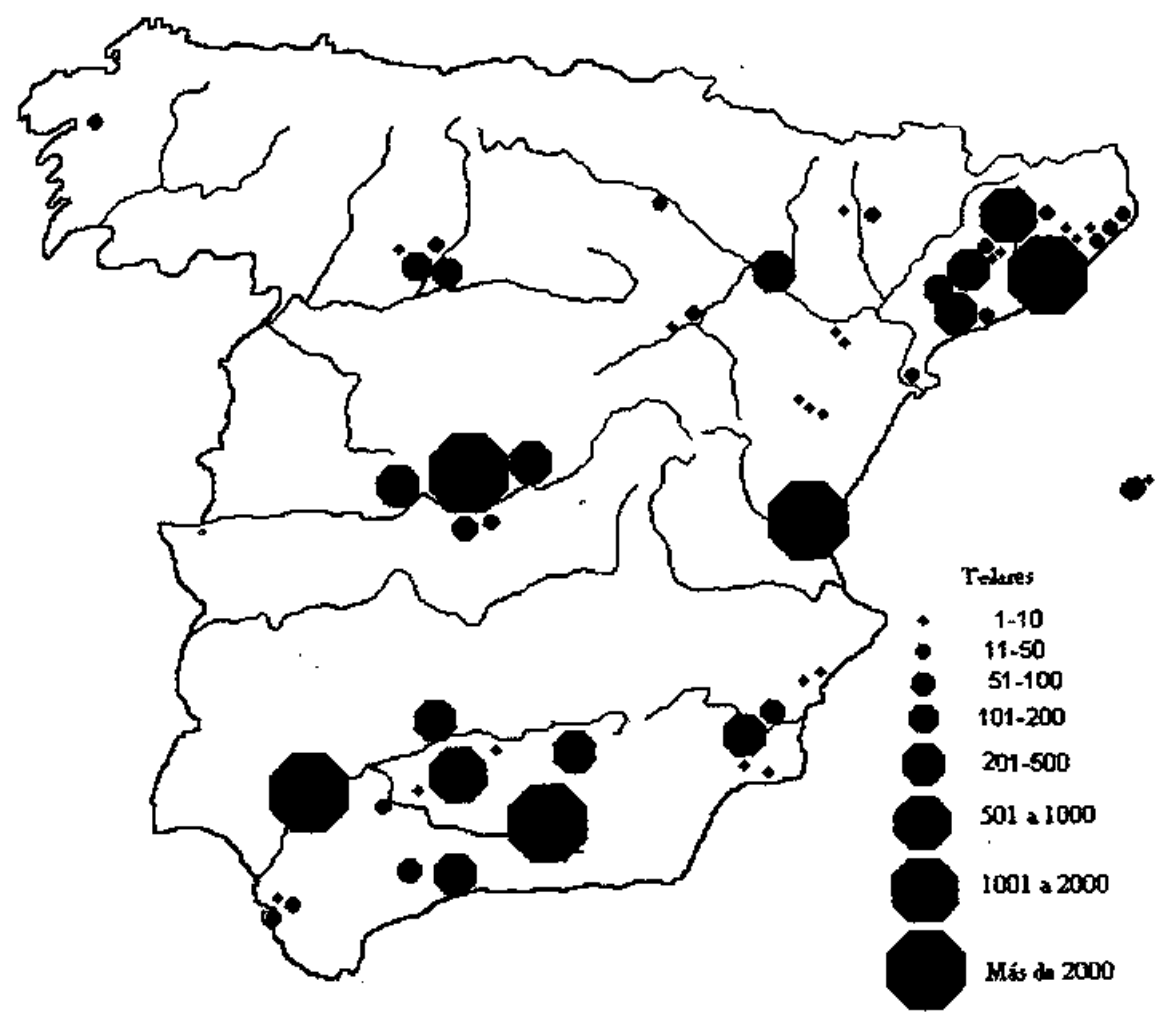

Por lo que se refiere a otras actividades de elaboración que también proliferaban por la Monarquía, destacaba el tratamiento de los cueros, aunque con enclaves muy significativos, cual fue el caso de Galicia, Cataluña, algunas localidades de Aragón (Calatayud, Brea), de Andalucía (Zalamea, Córdoba, Ubeda, Jaén y Granada) y de Castilla (Mota del Marqués, Segovia, Villarramiel) (Mapa VI). Del mismo modo, la alfareria se dispersaba por el territorio hispano, aunque Aragón (Alcorisa, Almonacil de la Sierra, Teruel, Calanda), Andalucía (Sevilla, Rambla, Puente Genil, Guadix, Andújar, Antequera) y Mallorca sobresalían, así como la jurisdicción de Valdejamuz en León o Puente del Arzobispo en Toledo, en tanto el trabajo del vidrio resultaba mucho más limitado (Mapa

Hipania, LVIII/3, núm. 200 (1998) 1021-1044 


\section{MAPA V}

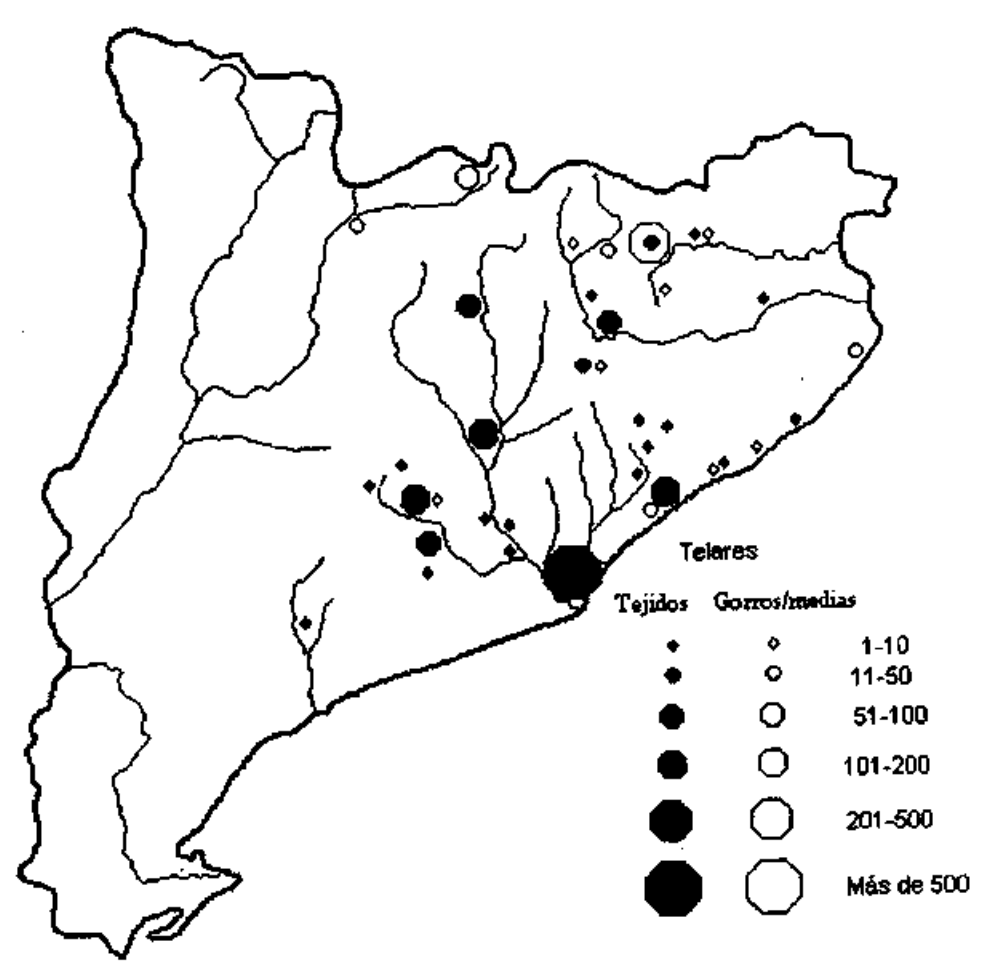

VII). En cuanto a la obtención de jabón, constitúa uno de los quehaceres relevantes de la España más próxima al Mediterráneo, allí donde el aceite y el alcalí estaban disponibles, como corroboraban Mallorca, Andalucía, Cataluña, Murcia y Aragón (Mapa VIII).

Situación distinta ofrecía la manufactura papelera, pues es clara la concentración en Cataluña, sin olvidar la localidad alicantina de Alcoy ${ }^{21}$, sobre la que

21 Se incorpora al mapa IX para Alcoy el dato aportado por CONEjERO, V.(1981): Gremios e inicios de la Revolución Industrial en Alooy. Alicante, pág. 195.

Hiqpania, LVIII/3, núm. 200 (1998) 1021-1044 


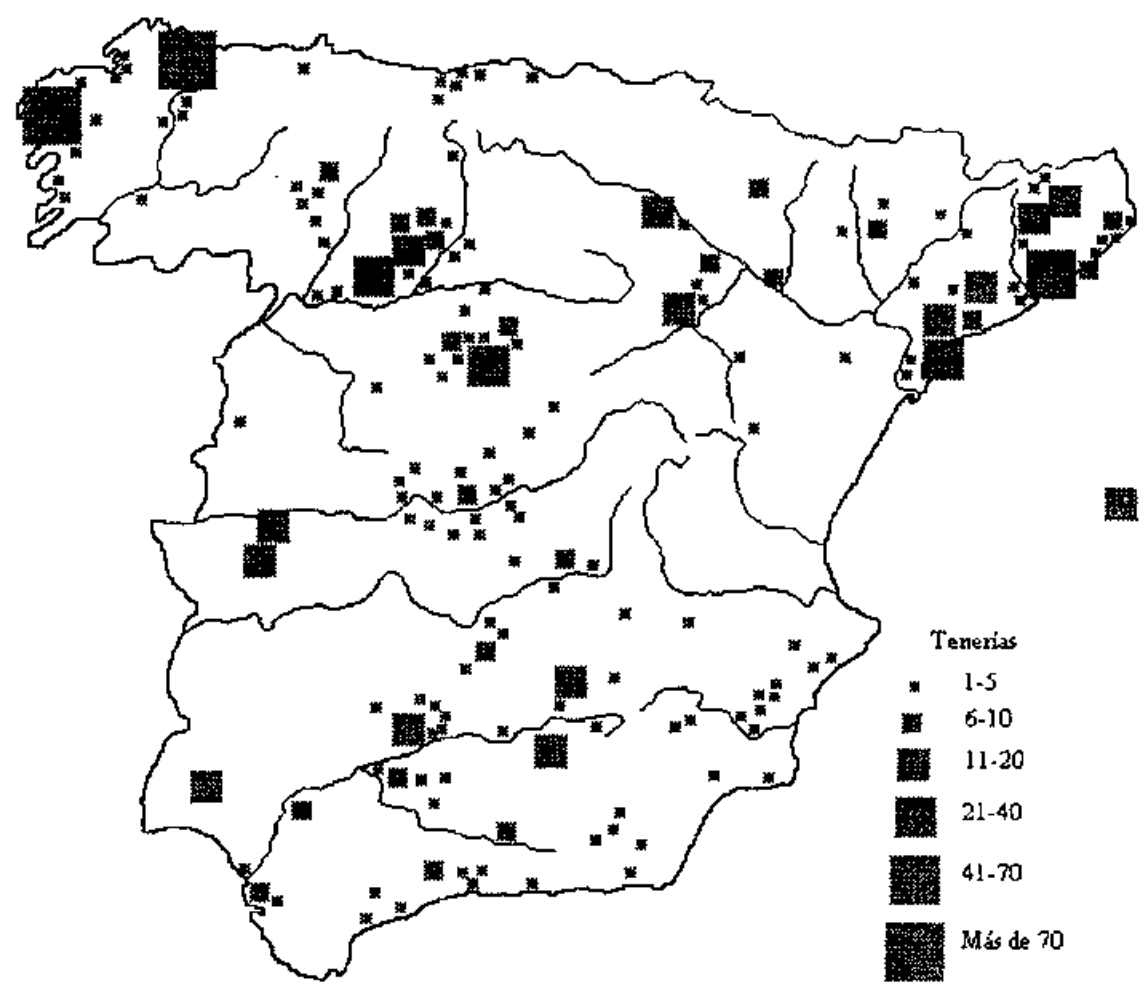

este Censo no dispone de información, junto a otros ámbitos menores de Aragón, en torno al Jalón, o de Andalucía (Mapa IX). Simultáneamente, la ubicación del trabajo en ferrerias y martinetes se sometía a los condicionamientos de la riqueza minera y del agua, lo que proporcionaba una distribución puntual (Mapa X) ${ }^{22}$, que se completaba con la transformación metalúrgica diversa en Olot, Ripoll, Sallent, Mataró, Albacete, Cartagena o Segovia.

22 Se incluye en el mapa $X$ información para el País Vasco procedente de BiLBAO-FERNÁN. DEZ (1982): «Auge y crisis de la siderometalurgia tradicional en el País Vasco (1700-1850)». La economía española al final del Antiguo Régimen. Alianza. Madrid, pág. 163.

Hiipania, LVIII/3, núm 200 (1998) 1021-1044 


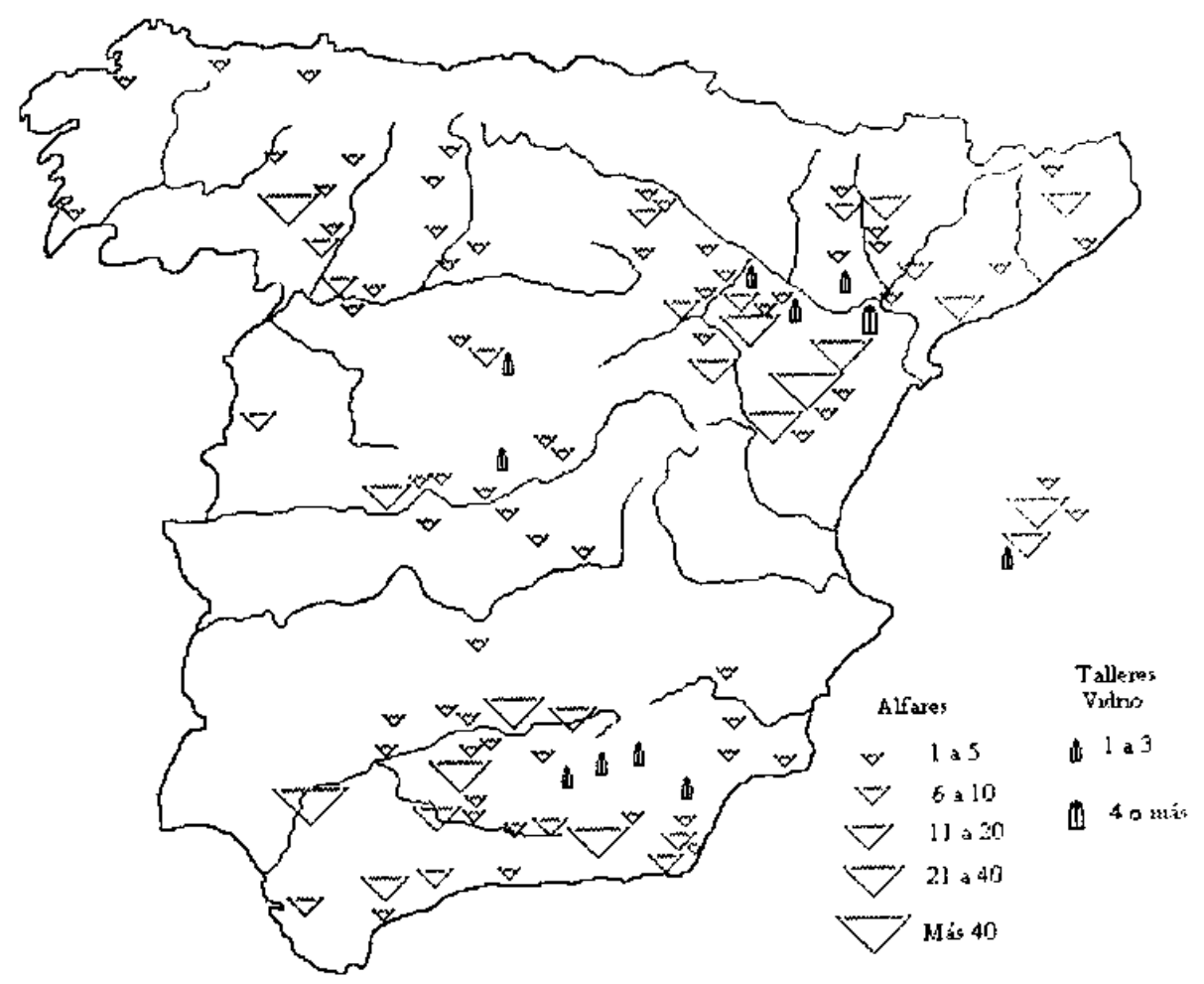

Las alusiones acerca de la elaboración de otras materias primas situaban a la manufactura de esparto de forma sobresaliente en Almería y Murcia, en tanto que la del cáñamo resultaba más difundida en Aragón, Rioja, Andalucía o Mallorca. No faltaron la construcción de barriles manifestada en Reus y San Feliu de Guixols o la obtención de tapones en esta última, Palafrugell y La Bisbal. Tampoco estuvo ausente la molienda de rubia y zumaque en Castilla, el blanqueo de la cera, la elaboración de almidón, cola y aguafuerte en Andalucía, la fabricación de aguardiente en Cataluña y Aragón, la elaboración de cerveza en Puerto de Santa María, de fideos en Jetez de la Frontera o la dedicación a la salazón de pescado en Marín, Cangas o San Salvador de Coiro, e incluso la insinuación de la construcción naval en Mataró.

Hiphania, LVIII/3, núrn. 200 (1998) 102t-1044 


\section{MAPA VIII ELABORACIÓN DE JABÓN}

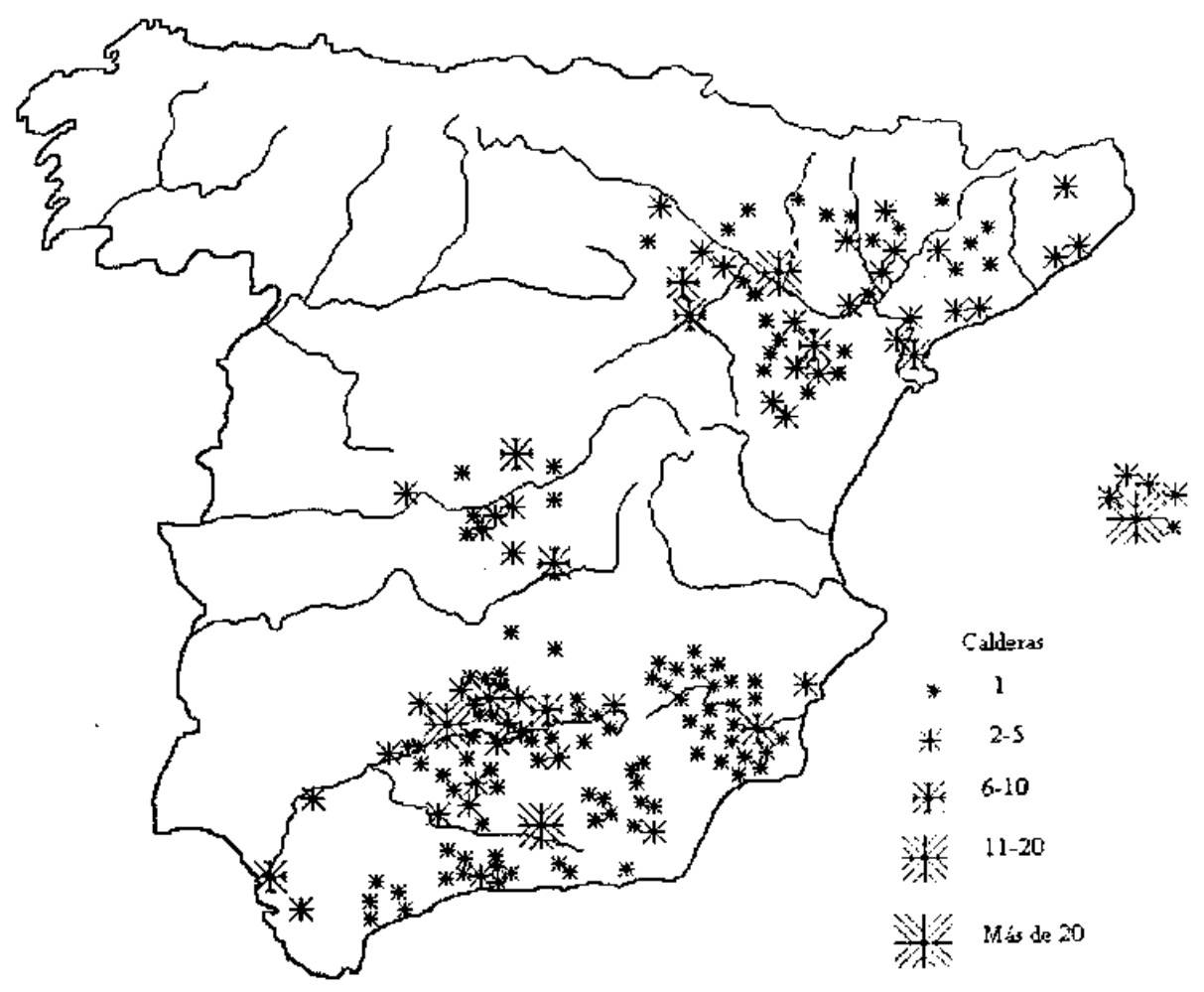

\section{II.2. En torno a las unidades de producción}

Las referencias esbozadas sobre la localización de estas actividades aporta una información que ha de ser matizada con otras variables que permitan precisar más la realidad productiva. En este sentido, merece atención el retrato de las unidades de producción involucradas en este sector, tal cual se reflejan en las respuestas. Estas confirman que el último cuarto del siglo XVIII se caracterizaba por la coexistencia del domicilio familiar, el taller gremial y las iniciativas empresariales privadas, que junto a las Manufacturas Estatales y otras fórmulas como las Casas de Misericordia, Hospicios, conventos o las promo-

Hispania, LVIII/3, núm. 200 (3998) 1021-1044 


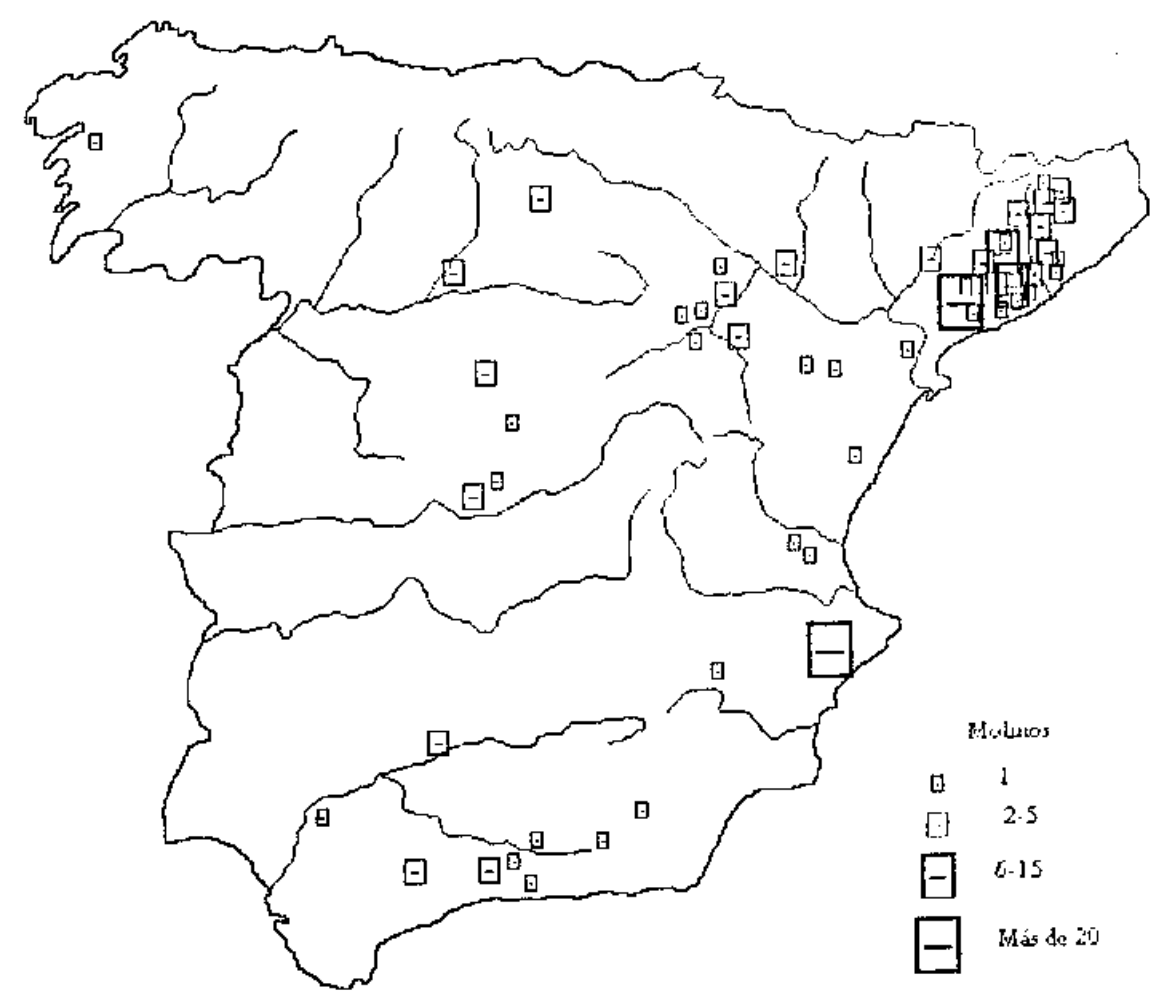

ciones de las Sociedades Económicas de Amigos del País, configuraban el abanico de quienes obtenían el output industrial español de la época. Aunque el recinto doméstico y el obrador gremial eran dominantes, el interés lo suscitaron quienes desde el ámbito particular, incluso enfrentándose a la ordenación corporativa, organizaron y gestionaron sus empresas con un nuevo talante y presentaron dimensiones a veces considerables, no sólo por la mano de obra movilizada sino por el utillaje empleado y su aprovechamiento aunque no concentraran todas las tareas en un mismo espacio ${ }^{23}$.

23 Torras Elías, J. (1987): «Fabricants sense fabrica. Estudi d’una empresa llanera d'Igualada (1726-1765)». Reģerques, n." 19, págs. 145-160.

Hispanja, LVIII/3, núm. 200 (1998) 1021-1044 


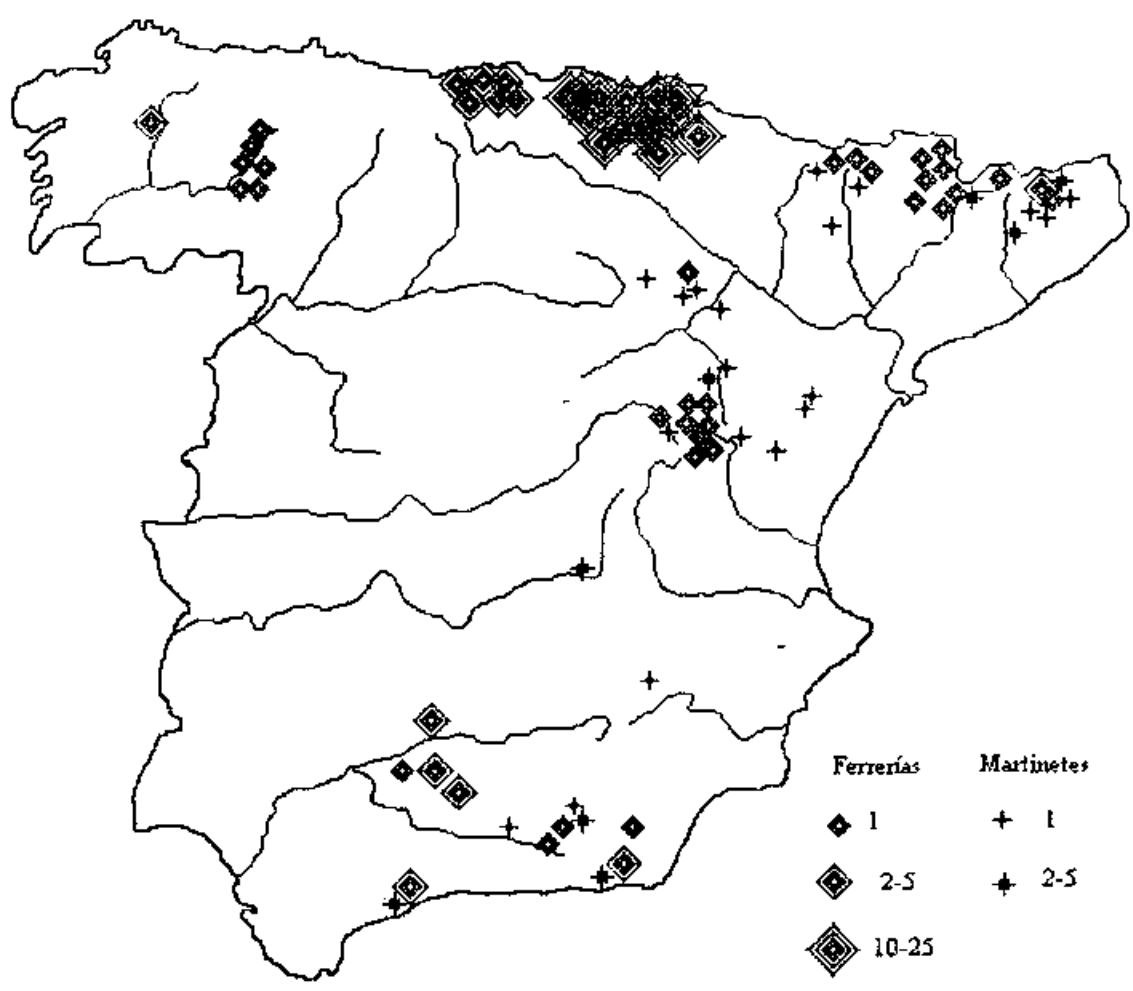

En efecto, a través del Censo de 1784 se ofrece la ocasión de conocer a estos empresarios individuales más sintonizados con los criterios de producción y calidad orientadas al mercado, que habían permanecido en el anonimato tras el telón documental de los grandes proyectos industriales del Estado. Los encontramos prácticamente en todos los subsectores, por supuesto en el tejido de algodón donde aparecen más tipificados como empresarios con fábrica o en la elaboración papelera, pero también en la lencería y en el pintado de lienzos, en el arte elitista de la seda, del que se desmarcaron los dedicados al tejido de medias o en el curtido donde la eliminación del deshonor parecía atraer nuevos proyectos.

En este haz de empresarios no pocos constituian la expresión de la incursión en la industria del capital mercantil, desde las Compañías de comercio a

I Ti.pania, LVIII/3, nưm 200 (1998) 1021-1044 
los comerciantes individuales. Algunas muestras de ello serían la razón social «Vico, Conti y Cía», del comercio de Cádiz, fabricantes de medias de seda en Puerto de Santa Maria, Félix Camplonch y Guarro titular de una fábrica de indianas en Mataró o Salvador Serralta, fabricante de medias de seda y de estopillas en la misma localidad, donde, por cierto, los comerciantes también gestionaban las calderas de jabón. Esta influencia de la esfera comercial en la manufactura llegó a ser exaitada por el Administrador de Murcia, precisamente porque, en su opinión, faltaba en su tierra, cuando expresaba «en todas partes son los mercaderes y comerciantes los que dirigen y vivifican las fábricas».

Tuvieran o no relación con el capital comercial estos empresarios protagonizaron iniciativas loables, sobre todo en aquellos casos en los que las circunstancias del mercado inmediato no eran óptimas. Tal acaeció cuando Cosme y Mariano Tormón, de Huesca, ensayaron nuevas telas (camelotes, calamandrías, anascotes...), Andrés Sierra instaló una fábrica de medias en Jaca, José García, pasamanero, montó un utelar de máquina» de catorce lanzaderas en Palencia que le permitía obtener cintas «de más duración que las inglesas» o cuando Juan de Jauriguiberri, fabricó objetos de peltre en Segovia. A veces, llegaron a fórmulas asociativas para afrontar el riesgo de la innovación, como verificaron Francisco Coll, Liserto y Pablo Badalia en Barcelona, para la obtención de antes y gamuzas de colores. Sin embargo, no todos, como era de esperar, triunfaron y para testimoniarlo se registra la frustración de la fábrica de pintar papeles y pieles que Luis Iriarte había erigido en Zaragoza o la de Salvador Revella para el tejido de algodón, en la misma ciudad, que no resistieron los inconvenientes. Entre estos empresarios no faltaron los de origen extranjero, cual era el caso de Juan Peiren, francés asentado en Seo de Urgell para tejer medias de algodón o el alemán Francisco José Neistar que se hacía cargo de la fábrica de estameñas de Sanlúcar bajo patrocinio de la Sociedad Económica de Amigos del País de la localidad.

\section{II.3. Acerca del proceso productivo}

El tipo de unidades de producción presentadas sugiere algunos de los rasgos del proceso productivo. En efecto, la atomización empresarial reinante y el marco reglamentario nos sitúan ante procedimientos técnicos atávicos, pues junto a quienes deseaban la novedad se encontraban aquellos otros reticentes al cambio, como expresaban los fabricantes de lana de Toledo que no estaban dispuestos a asumir el riesgo de ensayar nuevos productos y modificar sus métodos. No es extraño que se señale la generalizada utilización de la rueca en Galicia para el hilado del lino como factor opuesto al progreso del sector, aunque su uso también se mencionara en el otro extremo de la península, en Toledo, Huéscar y Doña Mencía. Igualmente, resultan recurrentes los testimonios sobre los esfuerzos, a veces inútiles, por difundir en el hilado de la seda el procedimiento Vaucanson, como sucedió en Granada, a pesar de la gestión de Felipot, entonces al frente de la Junta de Comercio de la ciudad nazari, y es que

Hípania, LVIII/3, núm 200 (1918) 1021-1044 
la generalidad del sector sedero seguía apegado a la fórmula española, con alguna excepción de hilado a la piamontesa en la fábrica de Murcia, ciertas localidades catalanas y Talavera donde se simultaneaba con un sistema intermedio mezcla de piamontés y español. No era menor la falta de progreso en las prácticas tintoreras, otra de las fases claves en el acabado de las telas y su buena salida posterior, tal cual hacían hincapié en Mataró. Quizá por esta realidad se exalten en el Censo, aunque sean minoritarias, las nuevas experiencias e inventos.

En sintonía con las inquietudes de quienes realizaron la Razón, se destacan los experimentos para hilar algodón, a fin de evitar su importación ya elaborado para tejer, y poder obtener mejores rendimientos. Estos eran los objetivos pretendidos con el nuevo torno presentado por el tintorero de Matató, Pablo Gallifa, o los esfuerzos de Severo Vila y Francisco Villa, de Tarragona, interesados en pedir modelos e instrumentos a la Real Sociedad Matritense, a Londres o en relacionarse con la fábrica de Peiren en Seo de Urgell. Mientras, las fábricas de indianas y las de pintados de lienzo realizaban un despliegue de artefactos que aludían a la progresiva importancia del capital fijo en el proceso productivo de algunos subsectores, aunque los dominantes seguían siendo los procesos intensivos en mano de obra. Así pues, también en el aspecto técnico la transformación se anuncia, pero la difusión tecnológica resulta muy lenta y a veces poco atractiva, al menos así se comunicaba desde Murcia al no prosperar la imitación de unos tornos de hilar ingleses procedentes de una captura naval.

Las circunstancias técnicas en las que se producía eran simultáneas de unas relaciones laborales cuya casuística se insinúa compleja. Trabajadores con habilidades en prácticas tradicionales, tanto en el ámbito doméstico como bajo la reglamentación gremial, convivían con el recurso al trabajo libre de quienes se incorporaban a las fábricas. Además, se sugerían sistemas de subcontratación de tareas y aureolas de pueblos cuya mano de obra se subordinaba a las necesidades de fábricas y fabricantes, no en vano se señalaba la existencia de casi 10.000 personas dependiendo de la fábrica de paños de Segovia ${ }^{24}$ y a numerosos pueblos de Toledo cuyas féminas trabajaban hilando para la Fábrica de Guadalajara, en detrimento de los tejedores del lugat. Fórmulas a las que se añadía la de las mujeres que laboraban en beneficio de comerciantes de quienes recibían la materia prima, tal cual confesaban en Mataró, Martoreil o Toledo. Rasgos todos ellos a los que se sumaría la temporalidad y multifuncionalidad de la mano de obra contabilizada en varios quehaceres industriales, como indicaban en Espejo, donde los «manipulantes» de los telares eran maestros de albañilería, o en Rambla, cuyos tejedores también se afanaban en las almazaras, aunque era la dedicación a la agricultura con la que más se compartían las jornadas de trabajo a lo largo del año.

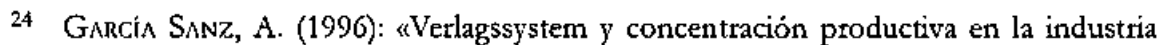
pañera de Segovia durante el siglo XVIII». Revista de Historia Industrial, 10, págs. 11-37.

Hitipania, LVIII/3, nüm. 200 (1998) 1021-1044 
Las consideraciones sobre quién produce y cómo se produce pueden resultar clarificadoras de los niveles de aprovechamiento tan dispares del equipamiento en todas las actividades que transmite el Censo, pero especialmente en las más difundidas, como heterogéneos eran también los rendimientos laborales o la cuantía y calidad del producto final. El grado de dedicación y los cri-terios orientadores del hecho productivo gravitan en la explicación de tal diversidad de situaciones en el sector transformador hispano. Algunas de estas observaciones se ilustrarian, por ejemplo, mediante el caso de Manlieu, localidad de 1145 habitantes, donde dos fabricantes con 23 telares obtenían 850 piezas al año de tejidos de algodón, mientras 28 telares dispersos conseguían 600 o que en Segovia catorce de los 65 fabricantes tejieran casi la mitad de los paños elaborados anualmente. Todos ellos son aspectos que pueden apreciarse con diferente detalle en las respuestas de esta fuente documental, al lado de referencias más parcas sobre el aprovisionamiento de materias primas.

\section{II.3. Tras la oferta productiva y su destino}

El volumen de producto proporcionado por el sector transformador como agregado para el Reino resulta arriesgado calibrarlo a partir del Censo de 1784, porque a veces faltan datos de producción, aunque si permite aprehender ciertas realidades locales $\mathrm{y}$, desde luego, percibir la composición y horizonte de consumo de este output industrial y los centros que pudieron aportar mayor cantidad en cada uno de los artículos.

Desde esta perspectiva se desprende que la generalización del tejido de lana en España se realizaba en torno a los tejidos de calidad más baja cuyo destino era el consumo lugareño o comarcal, mientras los géneros de calidad se distribúan por toda la península y llegaban a América. Así, los paños superfinos y finos ${ }^{25}$ de Segovia, Tarrasa, Sabadell, Alcoy, Enguera, Ezcaray, Grazalema, Guadalajara, Rubielos, Zaragoza y Teruel eran más limitados que los más bastos (docenos, milenos, burieles) o que las estameñas, cordellates, sayales y jergas que compartieron el mercado con las bayetas, menos frecuentes, de Antequera, Tarrasa, Palencia, Villarroya de los Pinares, Mora de Rubielos o Sigüenza ${ }^{26}$. Gama lanera que se

25 Se consideran paños superfinos los 30nos y más, y paños finos de 24nos a 26nos.

26 GARCIA SANZ, A. (1976): Desarrollo y crisis del Antiguo Régimen en Castilla la Vieja Economiay Sociedad en Tierra de Segovia. 1500-1814. Akal. Madrid. BtiNAul, J.M. (1991): La industria textil Hanera a Catakma, 1750-1870. El proves dindustriakqaaio al districte industrial de Sabadel/-Terrasa.- Barcelona. ARAClL, R.(1974): Industrialtzacio al Pais Valencia El cas d'Alowi- Eds. Climent.- Valencia. VALES, Y. (1986): Industria textily sacietat a la regio Alcoi-Ontżent (1780-1930). IVEI-Universitat Valencia.- Valencia. PARCjO, A. (1987): Industria dispersa e industrialización en Andalucia. El textil antequerano (1750-1900).- Málaga. Garcis, P. (1992): Evolución y crisis de la industria textil castellana. Palencia. 1750-1900.- Mediterráneo.Madrid. GonZÁLEZ ENCISO, A. (1983): «La industria lanera en la Provincia de Soria en el S. XVIIIs.Cuadernos de Intestigación bistórica, 7.- págs. 147-170. (1984): «La protoindustrialización en Castilla la Vieja en el S.XVIII), Revista de Histonia Económica, II, 3.- págs. 51-81. (1988): «La industria de la lana en el siglo XIII"”.- La economia de la Ilustración.- Cuadernos del Seminario «Floridablancas, 2.- Murcia.- págs. 71-98. 
completaba con fajas y cintas por doquier junto a mantas de Palencia o Lumbrales. Del mismo modo, la manufactura de lino/cáñamo ofrecía un predominio de lienzos caseros, si bien las fábricas de lona de Granada, Calatayud, Mataró o Santa Coloma de Farnes, la de mantele- ría de La Coruña o las de lienzos pintados de Barcelona o Puerto de Santa María ampliaban la oferta y su ámbito de comercialización al abastecimiento del Ejército, de la Corte o para el embarque al Nuevo Mundo ${ }^{27}$. La satisfacción de una demanda de élite española y americana era el objetivo de los trabajos de la seda, tanto los tradicionales de pasamanería de Granada, Toledo, Sevilla y Zaragoza, los tafetanes de Priego y Antequera o la velería de Manresa, como las medias de esta fibra procuradas en Barcelona, Mataró, Puerto de Santa María o Talavera, protegidas de la ofensiva comercial extranjera ${ }^{28}$. Otientaciones comerciales que compartían los tejidos de algodón (indianas, pañuelos, gorros y medias) que junto a alguna muselina y estopilla comenzaban a abrirse paso ${ }^{29}$. Entretanto, los sombreros apenas superaban el ámbito geográfico de su lugar de producción, a excepción de los de Mataró y Barcelona que recorrian el país haciendo la competencia a los segovianos y aragoneses, al decir de éstos.

La oferta de las tenerías hispanas se desgranaba, mayoritariamente, entre suelas, baquetas y badanas muy difundidas por la Monarquía para uso común, pero con centros proveedores destacados (Barcelona, Igualada, Alcalá, Brea y Daroca). Además, los cordobanes andaluces (Antequera) y mucho menos las gamuzas, que tenían en Vic su sede principal, afluían al mercado al igual que los pergaminos de Zaragoza, los becerrillos de Barcelona o los baldeses de Villarra-

LLorts, E. (1993): «La formación del «desierto manufacturero» extremeño: «el declive de la pañeria tradicional al final del Anciguo Régimen». Revista de Historia Industrial, 3, págs. 41-63.

27 CARMONA, X. (1990): El atraso industrial de Galicia. Auge y liquidación de las manufacturas textiles. 1750-1900.- Ariel.- Barcelona. ENCISO, L.M. (1963): Los establecimientos industriales españoles en el siglo XVIII.La Real Fábrica de Mantelería de La Coruña-- Valladolid. Dínz-TRECI IUELo, L. (1978); "La Real Fábrica de lonas de Granada y el suministro a los correos marítimos de América".- $A c$ tas de $11^{\circ}$ Congreso de Historia de Andalucia, siglo XVIII.- T. $1^{\circ}$.- pp. 141-152. IGLESIAS, J.J.(1991): Una ciudad mercantil en el sigh XVIII. E/ Puerto de Santa Maria.- Muñoz, Moya y Montraveta eds.Granada. DEYA, M.,(1986): «Introducción a la tipología de las actividades textiles rurales en Mallorca durante la segunda mitad del S.XVIII",- Estudis d'Historia Economica, n. ${ }^{\circ}$ 2. MANERA, C. (1988): «Manufactura textil y comercio en Mallorca, 1700-1830m. Revista de Historia económica, VI, n. ${ }^{\circ}$, págs. 523-555.

${ }_{28}$ GARZÓN, A (1972): La industria sedera en España. El arte de la seda en Granada.- Granada. Olivares Galvín, P. (1976): El cultivo y la industria de la seda en Murcia. Sigho XVIII.- Academia alfonso X el Sabio.- Murcia. Segura et alt. (1991): Elmon de la seda a Catalunya- Diputació.- Barcelona. GonZÁltż MUÑoz, M.C., (1973): «La Real Fäbrica de seda de Talavera de la Reina (1748-1851)». Hispania, 125.- págs. 629-660. Iglesias, J.J.(1991): Una ciudad mercantil en el siglo XVIII. El Puerto de Santa Maria.-Muñoz, Moya y Montraveta eds.- Granada.

29 SÁNCHIEZ, A.(1987): «Los inicios del asociacionismo empresarial en España: La Real Compañía de Hilados de algodón de Barcelona, 1772-1820m. Revista de Hacienda Pública Española, n. $108-109 .-$ p.262. (1989): «La era de la manufactura algodonera en Barcelona (1736-1839)». Estudios de Historia social, 48-49., pp. 65-113. TIIONPSON, J. K.J. (1994): Els origens de la industri. alitzacio a Catalunya. El cotó a Barcelona (1728-1832). Edicions. 62.- Barcelona.

Hispaniu, LVIII/3, núm 200 (1998) 1021-1044 
miel, Zaragoza y Barbastro, con una menor presencia de corregel y ante, este último declarado en Barcelona, Talavera, Puerto de Santa Maria y Baeza ${ }^{30}$. Un conjunto que parecía cubrir las necesidades del Reino acudiendo a flujos interiores como se aludía en situaciones concretas en Mallorca que se abastecía con algunas piezas de Barcelona.

Significativo resulta, igualmente, el análisis de la producción papelera ya que la aportación más destacada en el Censo tiene firma catalana (papel blanco, estraza y cartones), al no disponer de los datos de Alcoy. Mucho más alejada se presentaba la de Aragón, Andalucía, Toledo, enclaves de la Cuenca del Duero (Valladolid y Segovia) dedicados a la variedad de estanco y entrefina o la de Santa María de Iría especializada en papel de estraza ${ }^{31}$. Esta oferta permitía satisfacer la demanda de las prensas en la industria textil, del empaquetado de limones en Nerja, de los pilones de azúcar o de la especiería en Frigiliana, además de atender el requerimiento del Estado y del mercado americano.

La gama alfarera se destinaba, preferentemente, al consumo doméstico ${ }^{32}$, no obstante se elaboraban piezas finas en Alcora, Teruel, Plasencia de Jalón, Toledo, Segovia (fábrica de Tomás Ledesma) o en Oviedo, así como en Rambla, Antequera y Triana, cuyos objetos se difundían por toda la península y liegaban a las Antillas, mientras los recipientes de Villafeliche se utilizaba para las necesidades de la Fábrica de pólvora de la población y también practicaban la singladura americana. De forma similar, los objetos de vidrio eran populares con la excepción de los elaborados en la Real Fábrica de San Ildefonso ${ }^{33}$. Por su parte el jabón, blando o duro, se orientaba a proveer a las poblaciones donde se obtenía, con algunas excepciones declaradas como la de Mallorca que exportaba al continente europeo y a América o Lucena y Sevilla que lo comercializaban en Castilla y Las Antillas ${ }^{34}$.

30 TORRAS i RuBÉ, J.M.(1991): Curtidores y tenerias en Cataluña organización de un oficio preindustrial (Segles XVI-XIX).- Colomer Musmany.- Vic. MEIjIDE, A.(1986): «Las primeras industrias del curtido en Betanzos». Boletin do Seminario de Estudios Mariñans, 2-- págs. 27-45. SANS FERRAN, J.M. (1964): La industria española del curtido en el siglo XVTII.- Colomer Munmany.- Vic.

31 Delgado, J.M. (1991): «El paper».- Historia económica de la Catalunya contemporánia- Vol. 3. Barcelona.- págs. 205-232. Gayoso, G. (1994): Historia del papel en España-- Servicio de Publicaciones de la Diputación.- Lugo. GuTIÉrulzz Y Pocı, M. (1988): «La manufactura paperera catalana a la segona meitat del segle XVIII: Una introduccióm.- Revista Pedralbes, VIII.- Barcelona.- págs. 349-363. drid.

32 Seseñ Díez, N. (1997): Cacharreria popular. La alfarería de basto en España.- Alianza-- Ma-

33 Rutz Alcón, T. (1987): "Vidrio y cristal». Historia de las Artes Aplicadas e industriales en España.- Cátedra.- Madrid.- págs. 463-509. PAstor, P. (1994): Historia de la Raal Fábrica de cristales de San Ildefonso durante la época de la Ilustración. (1727-1818). - Madrid. HitLguera, J. (1991): «La Real Fábrica de vidrios de San Ildefonso: Una aproximación a su histora económicas.- Arte y tecnología del vidrio.- Fundación Centro Nacional del Vidrio.- Segovia.- págs. 61-86.

34 González Moreno, J. (1975); Las Reales Almonas de Sevilla (1397-1855). - Sevilla. RAMón Y MUÑoz, R. (1994): «La modernización y cambios en la industria jabonera españolan .VII Simposio de Historia Económica.- Barcelona.- pp. 28-40. 
En cuanto a la producción férrica el abastecimiento interior resultaba suficiente en general y además desde la Montaña y, sobre todo, desde el País Vasco, se transportaba a ultramar. Entretanto, la oferta metalúrgica disponía de los artículos de peltre segovianos y de la multiplicidad de objetos obtenidos en Ripoll y Olot, así como del hilo de latón de Sallent, de las armas de Igualada, anzuelos y agujas de Mataró, de los 36.000 a 42.000 cuchillos de Albacete o de los artículos obtenidos en Cartagena, algunos de los cuales abastecían al Arsenal ${ }^{35}$.

La cobertura de las necesidades corrientes y el impulso de la construcción naval arrastraron la manufactura de cáñamo para procurar sogas, cordelería, jarcia, pero también la fabricación de alpargatas en Aragón y Rioja ${ }^{36}$. Del mismo modo, las labores de esparto realizadas en Murcia y Almería ${ }^{37}$ o la de escobas de palma procedentes de la huerta murciana, sobre todo de Beniafar (más de medio millón) se distribuía por el país, en tanto que las mallorquinas se canalizaban a través de Marsella, ámbito al que acudían parte de los tapones de La Bisbal y Palafrugell.

En suma, la mayoría de la oferta productiva seguía teniendo un radio de consumo inmediato, aunque la orientada a los circuitos comerciales se presentaba dinámica, referida a productos de calidad, nuevos o bien a las variedades escasas de los tradicionales cuya demanda había que satisfacer. En cualquier caso, estas mercancías no se obtenían sin problemas.

\section{II.4. Relativo a estorbos y propuestas}

Fueran escuetas o prolijas las valoraciones incorporadas a las respuestas cifradas, expresaban que la actividad manufacturera tenía «estorbos» que dificultaban su progreso y esto suscitaba quejas y lamentaciones por parte de quienes a ella se dedicaban. En este sentido, es reiterativa por doquier la alusión a la carestía de las materias primas, ya que la falta de fondos de los empresarios, otro de los clamores, les impedía adquirirlas en el momento adecuado, debiendo acudir a la reventa, lo que suponía ser presa de la especulación de los intermediarios, hasta el punto de que en Toledo se apreciaba que los fabricantes se

35 BILlıA, L.M., FERNÁNDEZ, E.(1982); (Auge y crisis de la siderometalurgia tradicional en el Pais Vasco (1700-1850)m. La economia enpañola al final del Antiguo Régimen.- Alianza.- Madrid. ARroyo VALENTE, P. et alt. (1993): Ferrerias en Cantabria: Manufacturas de ayer, patrimonio de boy.- Santander. Graetus, E. (1990): Els origens industrials de Catalunya. Ripoll bressol de la industrialitzacio.Eds. Maideu.- Ripoll. LLUCIi, E. (1981): «La revolucio industrial a la Garrotxa (1777-1822)».Annales de l'Institut d'Estudis Gironins, vol. XXVII.- pp. 193-230. BENET Y CLARA, A. (1988): «La industrialització d'un poble de la Catalunya central; Sallent (1750-1808)». Revista Pedralbes, VIII, Barcelona, págs. 339-347. MALUQUER, J. (1984): «La producción de hierro en la farga catalana». Revista de Historia Económica, II, n. ${ }^{\circ} 3$, págs. 83-95.

36 GómEZ URDAÑEZ, J.L. (1983): «Economía y sociedad con los Borbones». Historia de la Rioja. Logroño, págs. 162-175. 1863. Almería.

Hi.phaniu, LVIH]/3, núm. 200 (1998) 1021-1044 
habían convertido en «meros mercenarios de las Casas de Comercio». También se mencionaba la falta de respeto por la normativa gtemial que repercutía en una merma de calidad de los productos, disminuyendo sus posibilidades de venta, aunque no faltaton quienes, como el Administrador de Segovia, apuntaron a las rigideces gremiales como causa de desdicha. Incluso se llegaba a aducir como obstáculo la falta de arraigo en la actividad, puesto que los fabricantes procuraban alejar a sus hijos del mundo artesanal en cuanto podian, para que se dedicaran a estudiar y obtuvieran otro status, lo que no favorecía la continuidad ni frecuencia de las dinastías empresariales dedicados a la industria. Todos estos inconvenientes que gravitaban sobre el proceso productivo, se agravaban con las dificultades de comercialización del producto ante las carencias en transportes adecuados pero también por la competencia extranjera en los tejidos y otros artículos, lo que dificultaba la salida de lo propio, ya que incluso los comerciantes preferían tratar con los foráneos dejando para mejor ocasión el negocio con los del Reino.

Ante estos inconvenientes se sugeria, también con insistencia, la creación de montepíos o compañías que permitieran disponer de stocks de materias primas a precios razonables, junto a lo cual se solicitaba más protección respecto a las mercancías extranjeras y a veces, incluso, respecto a las nacionales, así como la construcción y mejora de caminos. Se solicitaba, simultáneamente, ampliar los contratos de abastecimiento al Ejército de tejidos de lana que reclamaban desde Granada, Baeza o Pozoblanco, y de cordelería, como se indicaba también en Andalucía o en Aragón. Igualmente se argüía la necesidad de cualificar a la mano de obta mediante la instalación de Escuelas patrióticas, según la orientación de las iniciativas ilustradas. En definitiva, capitalización, protección, cualificación se sugerían como vías necesarias para estimular al sector manufacturero.

\section{CONSIDERACIONES FINAIES}

El boceto de la realidad manufacturera hispana que transmitía el Censo de 1784 debía impulsar la labor de los gobiernos ilustrados para su fomento, porque eran varios los «frenos» y no menores los que originarían algunas de las medidas solicitadas para aliviarlos, como la protección.

Pero la información recogida, además de su virtualidad para aplicar una determinada política industrial en la época, tiene el valor de una fuente documental que permite apreciar hoy, mediante los contrastes que recoge, el proceso de cambio por el que atravesaba el sector transformador hispano, posibilitando localizar no sólo los espacios sino a los protagonistas que con sus iniciativas pretendían romper con las rigideces que dificultaban el progreso, aunque se precisaran modificaciones más amplias en la mentalidad y en las pautas de consumo, vinculadas estrechamente al cambio de modelo económico.

Hitpania, LVIII/3, núm. 200 (1998) 1021-1044 


\section{APENDICE I}

«RAZON DE LOS PARTICULARES sobre que ha acordado la Real Junta General de Comercio, Moneda y Minas informen por mi mano los Intendentes y demás subdelegados de ella.

(1) Cuäntas fábricas hay en cada pueblo de tejidos anchos y angostos, de seda, lino, lana, cáñamo y algodón o mezcla, con distinción de clases, desde la más inferior a la más supetior, añadiendo la noticia de si el algodón con que se fabrican las indianas y cotonadas se hila en el pais o se introduce hilado de fuera del Reino.

[] Igualmente una razón puntual de las manufacturas de las mismas materias en telares de medias, o en labores de pasamanería, como también de tiradores de oro con telares de galones y fábricas de botones de oro y plata y asimismo de las de encajes de hilo y seda o blondas.

1. Las fábricas de sombreros de todas clases

(1) Las fábricas de lonas, jarcias y cordeleria de todas suertes y tamaños

(1) Las fábricas de estampar lienzos y papel.

[] Número de tornos para hilar seda, expresando ș son a la española, a la piamontesa o a la Vaucanson.

Q Número de tintes, expresando los colores regulares que dan y si para los azules usan de tinas o tinacos, y si se hace uso de la yerba que llaman pastel y de la orchilla.

- Número de batanes, si son de agua o de caballerías.

(1) Número de prensas de madera, de hierro o de bronce para tejidos de lana y de piedra para dar aguas a los de seda.

- Las fábricas de curtidos de todas clases, como corregel, o suela a la irlandesa, suela de la tierra, cordobanes, cabras, antes, gamuzas, baquetas, becertos, badanas, baldreses, pergaminos y tafiletes.

(1) Las fábricas de loza fina y basta

[] Las fábricas o molinos de papel y de cartones

(1) Número de calderas de jabón

C. Número de martinetes y ferrerias

[) Las manufacturas de esparto.

( Y las minas de metales y de carbón y ottas especies como caparrosa, alumbre, calamina, cobalto, etc. en actual beneficio y su estado con expresión de los dueños.

\section{PREVENCIONES}

0 En cada clase de género se hay de explicar el número de telares y gentes que ocupan, con la cantidad de piezas que en ellos se labraren al año.

[] En todas las fábricas se especificará igualmente todo lo que se labre en ellas al año por número, peso o piezas según sus clases y en las de alguna consideración se han de expresar también los nombres de los dueños.

[] Asimismo cualquiera ramo de industria de los que no se comprenden en esta razón o producciones útiles al comercio y fábricas, especialmente el zumaque, rubia, grana-kermes, granilla que llaman de Aviñon, gualda, pastel, etc,. ”

Madrid, 16 de diciembre de 1783

Firmado: D. Manuel de Nestares

Fuente: A. G. S., D. G. R. , II Remesa, leg. 503

Hipuniat, LVIII/3, núm. 200 (1998) 1021-1044 